\title{
Application of an Experimental Model for the Prevention of Recurrence after Cholecystectomy for Cholelithiasis
}

\author{
Seong-Ran Lee \\ Department of Medical Information, Kongju National University \\ lsr2626@naver.com
}

\begin{abstract}
This study is to apply an experimental model for the prevention of recurrence after cholecystectomy for cholelithiasis. The $\chi^{2}$-test was used to observe a statistically significant difference between experimental and control group. The pairwise t-test was done to compare the before and after application of health promoting ability in cholecystectomy patients. The results of this findings are as follows. Firstly, for dietary factors, the mean scores $(76.51 \pm 1.62)$ of respondents who had practiced the healthy lifestyle of onion intake a day after application of model a statistically significantly increased than respondents (57.86 \pm 2.65$)$ before intervention $(t=-1.48, p=.035)$. Secondly, for follow-up survey of physical factors, it was more highly estimated in the experimental group than control group, regardless of the time elapsed of 21 days after application of the experimental model. However, the intervention effect decreased more rapidly with time elapsed of 28 days after application in the experimental group as compared to the control group. Therefore, this model can improve communication among cholecystectomy patients by sharing clinical model. The experimental model can also help in reducing hospital expenditures by reducing duplicate investment on high cost of recurrence after cholecystectomy for cholelithiasis.
\end{abstract}

Keywords: Experimental model, Prevention, Recurrence, Cholecystectomy, Cholelithiasis

\section{Introduction}

Cholelithiasis is a relatively common disease, over $10 \%$ of the adult population of European countries have this disease. In most cases, cholelithiasis is discovered during a routine abdominal ultrasound, but also can give symptoms [1-2]. The main causes incriminated in the development of cholelithiasis are: genetic predisposition, the ratio women to men being 2-3/1 obesity, age, dyslipidaemia, diabetes hypertriglyceridaemia.

Cholelithiasis, occurs as a consequence of breaking the existing balance in the bile, where cholesterol, bile acids and lecithin are in a balance that ensures cholesterol solubilisation. An increase in the elimination of cholesterol or on the contrary, a decrease in bile acid secretion will lead to breaking the balance that ensures cholesterol solubilisation at its precipitation in the gallbladder, with cholesterol crystals development. Biliary stasis is another factor that favors the appearance of gallstones [3-4].

About 600,000 people receive a cholecystectomy in the United States each year. In a study of Medicaid-covered and uninsured U.S. hospital stays in 2012, cholecystectomy was the most common operating room procedure. A minority of the population, from $5 \%$ to $40 \%$, develop a condition called postcholecystectomy syndrome, or PCS. [11] Symptoms can include gastrointestinal distress and persistent pain in the upper right abdomen [5-6]. As many as 20\% of patients develop chronic diarrhea. The cause is unclear, but is presumed to involve the 
disturbance to the bile system. Most cases clear up within weeks or a few months, though in rare cases the condition may last for many years. It can be controlled with medication such as cholestyramine [7-8].

Cholecystectomy is the surgical removal of the gallbladder. It is a common treatment of symptomatic gallstones and other gallbladder conditions. Surgical options include the standard procedure, called laparoscopic cholecystectomy, and an older more invasive procedure, called open cholecystectomy. Laparoscopic cholecystectomy does not require the abdominal muscles to be cut, resulting in less pain, quicker healing, improved cosmetic results, and fewer complications such as infection and adhesions [9-11]. However, potentially serious complication is injury to the common bile duct, which connects the cystic and common hepatic ducts to the duodenum. An injured bile duct can leak bile and cause a painful and potentially dangerous infection. Many cases of minor injury to the common bile duct can be managed non-surgically. Major injury to the bile duct, however, is a very serious problem and may require corrective surgery. This surgery should be performed by an experienced biliary surgeon Abdominal peritoneal adhesions, gangrenous gallbladders, and other problems that obscure vision are discovered during about $5 \%$ of laparoscopic surgeries, forcing surgeons to switch to the standard cholecystectomy for safe removal of the gallbladder. Adhesions and gangrene can be serious, but converting to open surgery does not equate to a complication [1214].

In order to meet increasing demand for better patient care and upgrading clinical research, there is a need for the development of an empirical information system including clinical data collected from patients. This paper attempted a new approach to develop an information system.

Therefore, the purpose of this study is to apply a new experimental model for the prevention of recurrence after cholecystectomy for cholelithiasis. It is to develop an information system by constructing a new experimental model of patients' health practice, experimental results, and application data in patients with cholecystectomy. Specifically, current system procedure for the prevention of recurrence after cholecystectomy for cholelithiasis was analyzed. Information procedure as well as an information system for management of recurrence in cholecystectomy patients for cholelithiasis was investigated using a structured systems analysis and literature review on the information systems [1516]. Expected benefits of the information system include an improvement of consistency in patient management and reduction of duplicate prescriptions and test orders. In addition, this system can improve communication among patients by sharing common clinical model. In the long run, the experimental model can also help in reducing hospital expenditures by reducing duplicate investment on high cost of recurrence after cholecystectomy for cholelithiasis.

\section{Materials and Methods}

\subsection{Model Development Process}

This system is composed of input module, store module, analysis module, and result generation module. Linkage interface between the central database and each of the related module is implemented by the visual concept. User interface and the relational database table are supported for user's convenience. The detailed contents are summarized as follows. First, an experimental model is a method of analyzing, defining and designing the information architecture of organizations. It is a complex method dealing with interconnected data, processes, and strategies. Its goals are to understand issues and opportunities with current applications. Second, this system provides an experimental model with direction and a decision-making framework for cholecystectomy patients. 
Third, the results of an experimental model will be a technology evaluation and model strategy [Figure 1].

\subsection{Study Materials}

This program was developed through review of existing literature, assessment of cholecystectomy patients' model needs, available updates on information, web site analysis and solicitation of expert advice throughout the development process. Study participants were patients who were diagnosed with cholelithiasis at least 3 months ago by general surgery department of a general hospital in metropolitan area.

The data were collected by interview and self-administered questionnaire from February 3, 2014 through April 30, 2014. This program was totally consisted 114 persons, it has been divided into two parts. The experimental group of 57 patients which was assigned as group with information application, while the control group of 57 patients was assigned as group with no information application. The two groups are compared to know the difference of changes which affects health practice. On the other hand, the evaluation of patient satisfaction on the information system through information intervention was performed by two groups. In order to estimate the system efficiency, a follow-up test had been done for the health promoting behaviors of intervention program.

On the other hand, contents assigned for the prevention of recurrence after cholecystectomy for cholelithiasis are introduction, motivation, utilization, change, feasibility and effectiveness [Table 1].

\subsection{Research Instruments}

The effects of this program were measured before and after the test by performance ability adoption. The data collection tool was composed of totally 34 items This questionnaire covered with 8 items(age, gender, marital status, monthly income, education level, complication, another diseases, regular exercise) for general characteristics of subjects in this study, 18 items(body weight control, cholesterol control, stress control, onion intake, hypertension control, regular exercise, vegetable intake, meat intake, smoking, diabetes mellitus control, depression, tomato intake, dandelion tea drinking, chonggakgimchi intake, water drinking, kiwi intake, bilirubin level, alcohol drinking) for health promoting ability rate of before and after information application, and 8 items(convenience, efficiency, usefulness, reliability of the new experimental model/two for each item) for evaluation on the satisfaction of information system between two groups. It employed a five point scale. After collecting the survey questionnaires, the usable data was analyzed after excluding data deemed as insincere or unreliable. To see if the experimental group was equivalent to control group in the health-related pretest, the SPSS win 18.0 program was conducted to check the difference between the control and experimental group.

On the other hand, in order to estimate the information system efficiency, a follow-up test had been estimated the durability of health promoting ability rate for 35 days. The experimental group was applied by the experimental model for 3 sessions of information which lasted 30 minutes. During the period, the control group received no application. The control group was informated to conduct the program after finishing program for the experimental group. 
An Experimental Model

- A method of analyzing, defining and designing the information.

- A method dealing with interconnected data, processes, strategies, aims and efficient systems

Setting Goals and Application

- To understand key issues and opportunities with current applications

- To provide executives with direction and a decision-making framework for the prevention of cholelithiasis

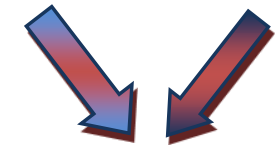

Development of Technology

- To develop technology for treating in cholecystecomy patients

- To provide an experimental model

Evaluation of An Experimental Model

- To verify and approve study results

-To define information effects and establish development priorities, proposals, and presentation

Figure 1. An Experimental Model for the Prevention of Recurrence after Cholecystectomy for Cholelithiasis

\subsection{Study Methods}

The Chi-square test was performed to compare the basic information of study subjects between two groups. The $\chi^{2}$-test was used to observe a statistically significant difference between experimental and control group. In addition, it was measured by percentage and number. The pairwise t-test was done to compare the before and after application of health promoting ability in cholecystectomy patients. It was also performed to determine a statistically significant difference in mean scores between the two groups to improve performance ability in cholecystectomy patients. All associations were considered to be statistically significant if the two-sided $\mathrm{P}$ value was .05. Or less. 
Table. 1 Contents Assigned for the Prevention of Recurrence after Cholecystectomy for Cholelithiasis

\begin{tabular}{|c|c|}
\hline Division & Contents \\
\hline \multicolumn{2}{|l|}{ Goals } \\
\hline Objective & $\begin{array}{l}\text { - Objective and procedure of an experimental model } \\
\text { - Effectiveness and assessment of database system }\end{array}$ \\
\hline Recognition & - Recognition and attitude of cholecystectomy patients \\
\hline \multicolumn{2}{|l|}{ Application } \\
\hline Change & $\begin{array}{l}\text { - Timely management as provided by information application } \\
\text { - Change of health condition }\end{array}$ \\
\hline Impact & $\begin{array}{l}\text { - Impact of health improvement after application } \\
\text { - Feasibility of a model after application to patients }\end{array}$ \\
\hline Improvement & $\begin{array}{l}\text { - Effectiveness of an experimental model } \\
\text { - Improvement of patients' health due to experimental model }\end{array}$ \\
\hline \multicolumn{2}{|l|}{ Evaluation } \\
\hline & $\begin{array}{l}\text { - Medical research and education data } \\
\text { - Useful information for medical management } \\
\text { - Evaluation of a model quality } \\
\text { - Communication method among cholecystectomy patients } \\
\text { - Statistical data for national health }\end{array}$ \\
\hline
\end{tabular}

\section{Results}

\subsection{General Characteristics of Subjects in This Study}

Table 2 presents general characteristics of subjects in this study. For age groups, it divided less than 39 years, 40 to 49 years, 50-59 years, and 60 years old or more. The respondent rate $(36.8 \%)$ of experimental group over age 60 was higher than the respondent rate $(24.6 \%)$ of control group. The respondent rate $(31.6 \%)$ of experimental group was lower than the respondent rate $(40.4 \%)$ of control groups, however, there was no significant difference for the age group in the 50-59 years between two groups.

A total of 59.6 percent of female respondents in the experimental group showed more than a total of 54.4 percent of female respondents in the control group according to gender. For marital status, a total of 56.1 percent of married respondents in the control group were lower than 64.9 percent of married respondents in the experimental group. On the other hand, for respondents who have another diseases, the proportion (66.7\%) of respondents in the experimental group showed a statistically significantly higher than the proportion $(40.4 \%)$ of respondents in control group $\left(\chi^{2}=9.64, p<.05\right)$.

Table 2. General Characteristics of Subjects in This Study

\begin{tabular}{|c|c|c|c|}
\hline \multirow[b]{2}{*}{ Variables } & Experimental group & Control group & \multirow[b]{2}{*}{$\chi^{2}$} \\
\hline & $\mathrm{N}(\%)$ & $\mathrm{N}(\%)$ & \\
\hline \multicolumn{4}{|l|}{ Age/yrs. } \\
\hline$\leq 39$ & $5(8.8)$ & 11(19.3) & 14.52 \\
\hline $40-49$ & $13(22.8)$ & $9(15.8)$ & \\
\hline $50-59$ & $18(31.6)$ & $23(40.4)$ & \\
\hline$\geq 60$ & $21(36.8)$ & $14(24.6)$ & \\
\hline
\end{tabular}




\begin{tabular}{|c|c|c|c|}
\hline \multicolumn{4}{|l|}{ Gender } \\
\hline Male & $23(40.4)$ & $26(45.6)$ & \multirow[t]{2}{*}{6.39} \\
\hline Female & $34(59.6)$ & $31(54.4)$ & \\
\hline \multicolumn{4}{|l|}{ Marital status } \\
\hline Unmarried & $20(35.1)$ & $25(43.9)$ & \multirow[t]{2}{*}{1.27} \\
\hline Married & $37(64.9)$ & $32(56.1)$ & \\
\hline \multicolumn{4}{|l|}{ Monthly income } \\
\hline$\leq 199$ & $19(33.3)$ & $17(29.8)$ & \multirow[t]{3}{*}{10.53} \\
\hline $200-399$ & $21(36.8)$ & $18(31.6)$ & \\
\hline $400 \leq$ & $17(29.8)$ & $22(38.6)$ & \\
\hline \multicolumn{4}{|l|}{ Education level } \\
\hline Under middle school & $15(26.3)$ & $18(31.6)$ & \multirow[t]{3}{*}{14.28} \\
\hline High school & $23(40.4)$ & $25(43.9)$ & \\
\hline Over college & $19(33.3)$ & $14(24.6)$ & \\
\hline \multicolumn{4}{|l|}{ Complication } \\
\hline Yes & $16(28.1)$ & $9(15.8)$ & \multirow[t]{2}{*}{$7.05 * *$} \\
\hline No & 41(71.9) & $48(84.2)$ & \\
\hline \multicolumn{4}{|l|}{ Another diseases } \\
\hline Yes & $38(66.7)$ & $23(40.4)$ & \multirow[t]{2}{*}{$9.64 *$} \\
\hline No & $19(33.3)$ & $34(59.6)$ & \\
\hline \multicolumn{4}{|l|}{ Regular exercise } \\
\hline Yes & $14(24.6)$ & $20(35.1)$ & \multirow[t]{2}{*}{12.81} \\
\hline No & $43(75.4)$ & $37(64.9)$ & \\
\hline Total & $57(100.0)$ & $57(100.0)$ & \\
\hline
\end{tabular}

$* \mathrm{P}<.05$

\subsection{Comparison of the Practice of Health Behaviors}

Table 3 represents the practice of health behaviors after application of an experimental model. For dietary factors, the mean scores $(76.51 \pm 1.62)$ of respondents who had practiced the healthy lifestyle of onion intake a day after application of model a statistically significantly increased than respondents $(57.86 \pm 2.65)$ before intervention $(t=-$ $1.48, \mathrm{p}=.035)$. On the other hand, there was a significant difference in practicing regular exercise after application of an experimental model $(\mathrm{t}=-1.83, \mathrm{p}=.000)$.

Table 3. Comparison of the Practice of Health Behaviors

\begin{tabular}{lccccc}
\hline & \multicolumn{2}{c}{ Before } & & & \\
\cline { 2 - 3 } Items & Mean \pm S.D & Mean \pm S.D & $\mathrm{t}$ & .417 \\
\hline Body weight control & $67.19 \pm 1.52$ & $56.94 \pm 3.18$ & & 2.73 & .652 \\
Cholesterol control & $84.65 \pm 3.87$ & $71.38 \pm 1.65$ & & 0.29 & .014 \\
Stress status & $72.53 \pm 0.28$ & $58.29 \pm 2.47$ & 5.61 & .035 \\
Onion intake & $57.86 \pm 2.65$ & $76.51 \pm 1.62$ & & -1.48 & .252 \\
Hypertension control & $72.39 \pm 0.28$ & $61.37 \pm 3.29$ & & 4.15 & .000 \\
Exercise & $36.19 \pm 3.05$ & $67.42 \pm 0.54$ & & -1.83 & .000 \\
Vegetable intake & $59.40 \pm 1.43$ & $83.74 \pm 3.16$ & -3.69 & .018 \\
Meat intake & $67.37 \pm 2.61$ & $46.53 \pm 1.75$ & & 0.47 & .000 \\
Smoking & $54.18 \pm 1.47$ & $35.08 \pm 1.92$ & & 2.51 & .579 \\
Diabetes mellitus & $67.42 \pm 3.63$ & $64.25 \pm 3.28$ & & 4.16 & .001 \\
Depression & $84.17 \pm 1.82$ & $69.71 \pm 0.47$ & 0.38 & \\
\hline
\end{tabular}




\begin{tabular}{lcccc}
\hline Tomato intake & $39.68 \pm 0.21$ & $52.94 \pm 0.82$ & -4.72 & .000 \\
Dandelion tea drinking & $12.92 \pm 3.82$ & $48.29 \pm 2.65$ & -2.59 & .000 \\
Chonggakgimchi. & $31.57 \pm 1.45$ & $64.15 \pm 4.27$ & -0.74 & .000 \\
Intake & & & & \\
Water drinking & $58.16 \pm 3.27$ & $85.32 \pm 3.18$ & -3.52 & .000 \\
Kiwi intake & $27.54 \pm 0.49$ & $62.19 \pm 0.72$ & -1.86 & .000 \\
Bilirubin level & $89.72 \pm 0.51$ & $74.39 \pm 0.67$ & 0.49 & .273 \\
Alcohol drinking & $76.18 \pm 2.48$ & $42.62 \pm 2.58$ & 4.15 & .000 \\
\hline
\end{tabular}

\subsection{Change of Health Promoting Ability between Two Groups}

Figure 2 compares the change of health promoting ability before and after application of the experimental model between two groups. For follow-up survey of physical factors, it was more highly estimated in the experimental group than control group, regardless of the time elapsed of 21 days after application of the experimental model. However, the intervention effect decreased more rapidly with time elapsed of 28 days after application in the experimental group as compared to the control group.

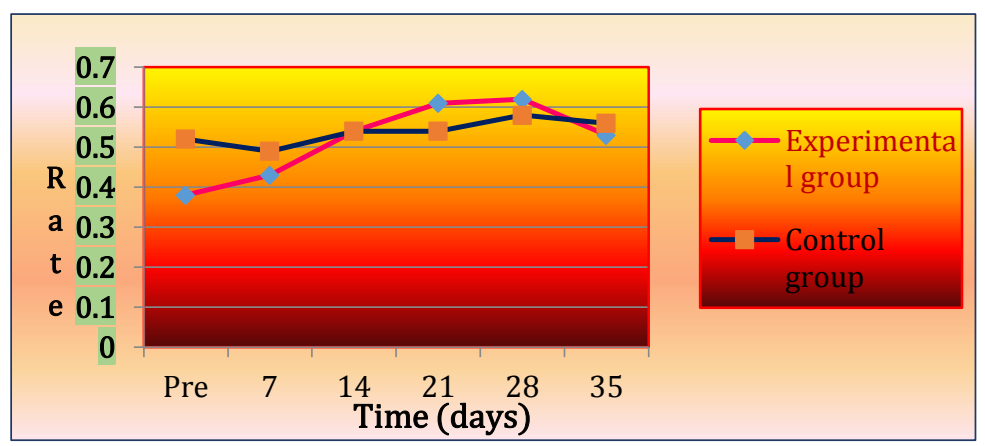

A. Change of Physical Factors Before and After Application

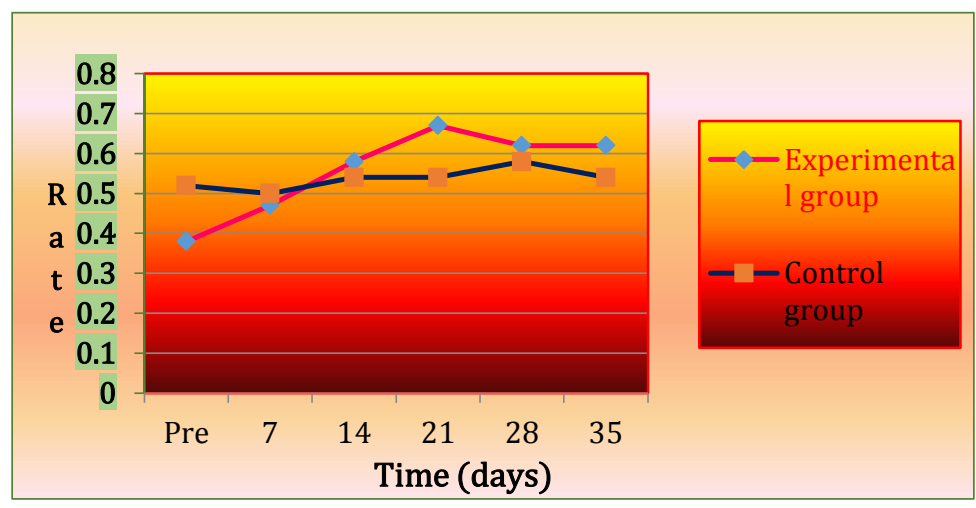

B. Change of Dietary Factors before and After Application

$$
\begin{aligned}
* \text { Slope }=\frac{\triangle \mathrm{Y}}{\Delta \mathrm{X}} & \text { Where } \triangle \mathrm{X}: \text { time interval } \\
& \triangle \mathrm{Y}: \text { variation of health promoting ability } \\
* \text { Ratio }=\frac{\triangle \mathrm{Ya}}{\Delta \mathrm{Yb}} & \text { Where } \triangle \mathrm{Yb}: \text { performance ability before application of experimental model } \\
& \triangle \mathrm{Ya}: \text { performance ability after application of experimental model }
\end{aligned}
$$

Figure 2. Change of Health Promoting Ability Before and After Application 


\subsection{Evaluation of User's Satisfaction on the Experimental Model}

Table 4 presents the evaluation of user's satisfaction on the new experimental model between two groups. For the user's convenience of the experimental model, it was easier to use the model in the experimental group $(37.12 \pm 2.18)$ than the control group (34.65 $\pm 1,28)$. For effectiveness of the new experimental model, the respondents who were easier to connect with the experimental model $(32.76 \pm 0.54)$ showed a lower rate in experimental group than the control group $(37.19 \pm 0.16)$. There was a significantly lower difference in experimental group $(\mathrm{t}=-5.29, \mathrm{p}=.035)$ than control group. On the other hand, for usefulness of the new experimental model, the experimental groups $(38.55 \pm 2.41)$ who showed useful information of health management were a higher rate than that of control groups $(26.28 \pm 0.61)$. There was a significant difference between two groups $(\mathrm{t}=2.97, \mathrm{p}=.000)$.

Table 4-1. Evaluation of User's Satisfaction on the Experimental Model

\begin{tabular}{|c|c|c|c|c|}
\hline Items & $\begin{array}{c}\text { Experimenta } \\
\text { Group } \\
\text { Mean } \pm \text { S.D. }\end{array}$ & Mean \pm S.D. & $\mathrm{t}$ & $\mathrm{p}$ \\
\hline \multicolumn{5}{|l|}{$\begin{array}{l}\text { Convenience of the new } \\
\text { experimental model }\end{array}$} \\
\hline Easy to use the model & $37.12 \pm 2.18$ & $34.65 \pm 1.28$ & 4.18 & .192 \\
\hline Easy to contact to operator & $34.69 \pm 1.35$ & $27.41 \pm 2.42$ & 2.54 & .000 \\
\hline \multicolumn{5}{|l|}{$\begin{array}{l}\text { Effectiveness of the new } \\
\text { experimental model }\end{array}$} \\
\hline $\begin{array}{l}\text { Easy to connect with } \\
\text { experimental model }\end{array}$ & $32.76 \pm 0.54$ & $37.19 \pm 0.16$ & -5.29 & .035 \\
\hline Fast to search information & $29.41 \pm 2.60$ & $27.82 \pm 2.19$ & 1.27 & .349 \\
\hline
\end{tabular}

Table 4-2. Evaluation of User's Satisfaction on the Experimental Model

\begin{tabular}{|c|c|c|c|c|}
\hline Items & $\begin{array}{c}\begin{array}{c}\text { Experimental } \\
\text { group }\end{array} \\
\text { Mean } \pm \text { S.D. }\end{array}$ & $\begin{array}{c}\begin{array}{c}\text { Control } \\
\text { group }\end{array} \\
\text { Mean } \pm \text { S.D. }\end{array}$ & $\mathrm{t}$ & $\mathrm{p}$ \\
\hline $\begin{array}{l}\text { Usefulness of the new } \\
\text { experimental model }\end{array}$ & & & & \\
\hline $\begin{array}{l}\text { Useful information to the } \\
\text { management of health }\end{array}$ & $38.55 \pm 2.41$ & $26.28 \pm 0.61$ & 2.97 & .000 \\
\hline Easy to understand the system & $34.97 \pm 0.65$ & $32.73 \pm 1.28$ & 1.79 & .163 \\
\hline \multicolumn{5}{|l|}{$\begin{array}{l}\text { Reliability in the process of } \\
\text { decision making }\end{array}$} \\
\hline Accurate contact & $30.62 \pm 3.18$ & $28.07 \pm 2.59$ & 3.29 & .628 \\
\hline Detailed contents & $38.59 \pm 0.45$ & $31.56 \pm 0.12$ & 0.93 & .041 \\
\hline
\end{tabular}

\section{Discussion}

This study is to apply a new experimental model for the prevention of recurrence after cholecystectomy for cholelithiasis. The implementation of the experimental model brought better quality of life to cholecystectomy patients.

As a result of this study, for the comparison of health behavior, it showed statistically significantly positive changes in performance ability such as stress control, tomato and onion intake. It diminished the progression rate of cholelithiasis. The finding was similar 
to the previous studies on the digestive disease[17-18]. This study suggests that individuals with cholecystectomy should be targeted for specific health behavioral intervention to prevent the progression of cholelithiasis. Based on the results obtained by the study, it is anticipated that this paper may be used as basic data for developing and interventing health behavior for cholecystectomy patients. However, in order to maintain desirable health, it needs periodic education programs in cholecystectomy patients.

Until the present, the limitation of cholecystectomy patients lies in that there is nothing put into action despite the increase of knowledge. The results of this study will help in improving practice behavior for the prevention of cholelithiasis. Thus, this paper indicated that the implemented systematic intervention showed significant positive effects on the life of subjects and health behavior. The quality of life in the experimental group has been enhanced as time passes by compared to control group. It showed that it is an effective program for the prevention of cholelithiasis. Therefore, the experimental model for cholecystectomy implemented by intervention research is quite meaningful in evidencebased program development.

The patients with Crohn's disease who had moderate exercise level and who were under diet care had better quality of life. The finding was similar to the previous studies on the intestine disease [19-20]. Current practice of smoking in cholecystectomy patients were obtained through intervention of information system. Therefore, adequate health practice behavior in cholecystectomy patients will improve their quality of life in accordance with appropriate experimental model. The development of the experimental model is so essential to cholecystectomy patients. For successful model of this study, this paper had tried to provide various information to enhance the practice rate of health behavior in cholecystectomy patients. So, there were many changes which improve the quality of life in cholecystectomy patients using the experimental model.

As a result of this study, it is considered that the practice rate of health behaviors such as non-alcohol drinking, depression control, and water drinking will contribute in cholecystectomy patients by the application of the experimental model. The reason is why this paper will contribute to new approach methods of the development administration. For bilirubin level, the experimental group was lower than control group after intervention. The user's satisfaction rate of the experimental model was relatively high. The methodology and the results presented here will contribute to improve the development of the experimental model. Also, this experimental model will perform the health promoting behaviors based decision-making on health strategies to reduce the risk of cholelithiasis.

This study found that the experimental model have a positive perception on the effectiveness of the experimental model. In particular, the result of the analysis confirmed that the convenience of the experimental model did directly contribute to the reduction of the patients' cholelithiasis. Meanwhile, one of the most obvious contribution of cholelithiasis on the experimental model was to improve transparency and reliability in the process of decision making of patients. The results of this study will be competitive power of various organizations such as nations, researches, health, and educations, and the importance of data quality in the experimental model will increase day by day.

Thus it shows good possibilities in effective model. Furthermore, by providing the networking information in interaction among cholecystectomy patients, the experimental model enables users to understand the application effects in viewpoint of experimental model.

\section{Conclusion}

This study is to apply an experimental model for the prevention of recurrence after cholecystectomy for cholelithiasis. The implementation of the experimental model brought better quality of life to cholecystectomy patients. The study of the results are as follows. 
Firstly, for respondents who have another diseases, the proportion (66.7\%) of respondents in the experimental group showed a statistically significantly higher than the proportion $(40.4 \%)$ of respondents in control group $\left(\chi^{2}=9.64, \mathrm{p}<.05\right)$.

Secondly, for the intake of an onion, the mean scores $(76.51 \pm 1.62)$ of respondents who ate an onion a day after application of model a statistically significantly increased than respondents $(57.86 \pm 2.65)$ before intervention $(\mathrm{t}=-1.48, \mathrm{p}=.035)$.

Thirdly, for follow-up survey of physical factors, it was more highly estimated in the experimental group than control group, regardless of the time elapsed of 21 days after application of the experimental model. However, the intervention effect decreased more rapidly with time elapsed of 28 days after application in the experimental group as compared to the control group.

Fourthly, for effectiveness of the new experimental model, the respondents who were easier to connect with the experimental model $(32.76 \pm 0.54)$ showed a lower rate in experimental group than the control group (37.19 \pm 0.16$)$. There was a significantly lower difference in experimental group $(\mathrm{t}=-5.29, \mathrm{p}=.035)$ than control group.

Therefore, expected benefits of the experimental model include an improvement of consistency in patient management and reduction of duplicate prescriptions and test orders. In addition, this model can improve communication among cholecystectomy patients by sharing common clinical model. In the long run, the experimental model can also help in reducing hospital expenditures by reducing duplicate investment on high cost of recurrence after cholecystectomy for cholelithiasis.

\section{Acknowledgements}

I would like to express my deepest appreciation to study subjects who have participated in the application of an experimental model for the prevention of recurrence after cholecystectomy for cholelithiasis in a busy life. The experimental model will provide effective services in multi-environments to cholecystectomy patients and help in improving their health conditions.

This paper was a revised and expanded version of a paper entitled "Development and Application of An Integrated Information System to Improve Self-care Behaviors in Cholecystomy Patients" gave a presentation at the $4^{\text {th }}$ International Conference on Convergence Technology 2014, July 2-5, 2014.

\section{References}

[1] Statistics Korea, Annual Report on the Cause of Death Statistics. 13, 15 (2011)

[2] G. K. Glantzounis, A.D. Tselepis, A.P. Tambaki, T.A. Trikalinos, A.D. Manataki, D.A. Galaris, E.C.Tsimoyiannis, A.M. Kappas, Laparoscopic Surgery-induced Changes in Oxidative Stress Markers in Human Plasma, Surg Endosco, vol. 15, 1315, 1319 (2001)

[3] H. Koksal and S. Kurban, Total Oxidant Status, Total Antioxidant Status, and Paraoxonase and Aryleslerase Activities During Laparoscopic Cholecystectomy Clinics, 65, 285, 290 (2010).

[4] M. Sare, I. Yilmaz, D. Hamamci, M. Birincioglu, M. Ozmen, O. Yesilada, The Effect of Carbon Dioxide Pneumoperitoneum on Free Radicals, Surg Endose, 14, 649, 652 (2000).

[5] S. I. Zacks, R.S. Sandler, R. Rutledge, R.S. Brown, A Population-based Cohort Study Camparing Laparoscopic Cholecystectomy and Open Cholecystectomy Am J. Gastroentrol, vol. 97, 334, 340 (2002)

[6] B. Zulfikaroglu, M. Koc, A. Soran, F.K. Isman, I. Cinel, Evaluation of Oxidative Stress in Laparoscopic Cholecystectomy, Surg Today vol. 32, 869, 874 (2002)

[7] R. S. Chamberlain, S.V. Sakpal, A Comprehensive Review of Single-Incision Laparoscopic Surgery and Natural Orifice Transluminal Endoscopic Surgery Techniques for Cholecystectomy J, Gastrointestinal Surg. vol. 13, 1733, 1740 (2009)

[8] A. Chow, S. Purkayastha, P. Paraskeva, Appendectomy and Cholecystectomy Using Single-Incision Laparoscopic Surgery ; The First UK Experience, Surg. Innov, vol. 16, 211, 217 (2009)

[9] P. D. Hayhew, Advanced Laparoscopic Procedures (Hepatobiliary, Endocrine) in Dogs and Cats, Vet Clin North Am Small Anim Pract, vol. 39, 925, 939 (2009)

[10] P. D. Mayhew, S.J. Mehler, Radhakrishnan A, Laparoscopic Cholecystectomy of Uncomplicated Gallbladder Mucocele in Sixdogs, Vet Surg, vol. 37, 625, 630 (2008) 
[11] G. Sakorafas, G. Anagnostopulos, V. Stafyla, Elevation of Serum Liver Enzyme After Laparoscopic Cholecystectomy NI Med J, vol. 118, U1317 (2005)

[12] E. Kuhry, W. Schwent, R. Gaupset, U. Romild, J. Bonjer, Long-term Outcome of Laparoscopic Surgery for Colorectal Cancer, A Cochrane Systematic Review of Randomized Controlled Trials Cancer Treat Rev. vol. 34, 498, 504 (2008)

[13] S.R. Lee, The Effect of An Integrated Information System Adoption for Performance Ability Improvement in Hypertensive Patients, IJSEIA. vol. 3, 435, 442 (2014)

[14] S. Kugathasan, S.L.Werlin, Martinez A, Rivera MT, Heikenen JB, Binion DG, Prolonged Duration of Response to Infliximab in Early But Not Late Pediatric Crohn's Disease, J, Gastroenterol. vol. 95, 3189, 3194 (2000)

[15] Ministry of Security and Public Administration, Information System Audit Standard Revision (2010)

[16] National Information Society Agency, The Commentary on the Information System Audit Standards, V3 National Information Society Agency (2009)

[17] Donald, R. T, Matthias, S, and Willima, T. W. Efficient Global Optimization of Expensive Black-Box Function, Journal of Global Optimization. vol. 13, 456, 491 (2008)

[18] Remicade Approved for Children with Crohn's Disease, FDA, Consum. 40, 46 (2006)

[19] U. Tomas, J. Ganiron, Effect of Sawdust As Fine Aggregate in Concrete Mixture for Building Construction, IJAST. vol. 63, 73, 82 (2014)

[20] S.R. Lee, The Application Effect of A Medical Information Management System for the Prevention in of Depression in Mastectomy Patients, IJBSBT. vol. 5, 57, 64 (2013)

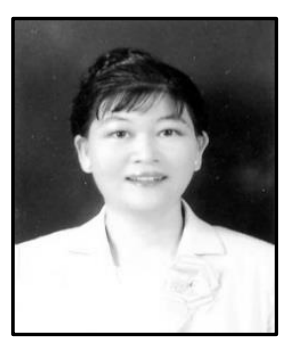

\section{Author}

Seong-Ran Lee received the B.S. degree in Consumer Science from Seoul National University, Korea in 1987. She received the M.S. degree in Public Health from Seoul National University, Korea in 1992 and Ph.D. in the same area from Catholic Medical College, Seoul, Korea in 2000. Currently, she is a Professor in the Department of Medical Information, Korea. Her present research interest is medical information. 
International Journal of Control and Automation Vol. 8, No. 6 (2015) 